\title{
¡España se prepara! La ayuda americana en la modernización y colonización agraria en los años cincuenta
}

\author{
Francisco Javier Martínez Rodríguez, Andrés Sánchez Picón \\ Y JOSÉ JOAQUín GARCía GóMEZ
}

\begin{abstract}
PALABRAS CLAVE: regadío, colonización, ayuda americana, transferencia tecnológica.
\end{abstract}

CÓDIGOS JEL: N34, N40, N54, N74.

\footnotetext{
7 a apertura internacional en España en los cincuenta y el avance económico del país a partir de finales de dicha década tuvo como nexo de unión el sector agrario y la ayuda de los Estados Unidos. La modernización de la agricultura española terminó con el atraso secular de un sector clave en el desarrollo económico a través de la ruptura de un cuello de botella tecnológico para el que fue necesario el concurso norteamericano. El objetivo del presente artículo es analizar en qué consistió la ayuda americana y la importancia trascendental que supuso para el desarrollo agrario español, tanto en la política de colonización del INC como en los programas de importación de maquinaria o en la transferencia de conocimientos técnicos. Para ello, se ha estudiado el fondo del INC disponible en el Archivo Central del Área de Agricultura y Alimentación del Ministerio de Agricultura, Alimentación y Medio Ambiente. Así, en la introducción se presenta un estado de la cuestión de la situación del sector agrario español en los años cincuenta, en el siguiente apartado se analiza la ayuda americana a España, en el tercero y cuarto se explica la aplicación de la enmienda $\mathrm{McCa}$ rran y la Public Law 480 en el INC, y en el quinto hacemos un balance global de la ayuda americana y su impacto en el desarrollo agrario español. El artículo termina con unas conclusiones donde se demuestra la importancia de esta ayuda.
} 


\title{
Spain gets ready! US help in agricultural modernization and colonization during the 1950s
}

\author{
KEYWORDS: irrigated land, settlement programs, American aid, \\ technological transfer.
}

JEL CODES: N34, N40, N54, N74.

The opening of Spain to international political relations in the 1950 s and the
economic growth that began at end of that decade was linked to the agricul-
tural sector and aid from the United States. American tender was needed to break the technological bottleneck, modernise Spanish agriculture and end the secular backwardness of a key sector for economic development. The aim of this article is to analyse the transcendental importance of US aid in Spanish agrarian development, through the INC colonization policy, machinery import programmes and knowledge transfer. This study is based on the INC documentary collection in the Central Archive of the Agriculture and Food Area of the Ministry of Agriculture, Food and Environment. In the introduction, we describe the situation of the Spanish agrarian sector in the 1950s, followed by an analysis of US aid to Spain in Section 2. In the third and fourth sections, we explain the application of the McCarran Amendment and Public Law 480 in the INC, and in the fifth section we look at the overall effects and impacts of US aid in Spanish agricultural development. The article ends with some conclusions that demonstrate the importance of this aid.

Recepción: 2017-12-05 - Revisión: 2018-03-10 • Aceptación: 2018-03-16

Francisco Javier Martínez Rodríguez [orcid.org/0000-0002-0910-1911] es investigador postdoctoral en el Grupo de Investigación Desarrollo Económico y Economía Agroalimentaria de la Universidad de Almería. Dirección para correspondencia: Departamento de Economía y Empresa, Facultad de Ciencias Económicas y Empresariales, Universidad de Almería, Ctra. Sacramento, s/n, 04120 La Cañada de San Urbano (Almería, España).C.e.:fjmartinezrodriguez@gmail.com

Andrés Sánchez Picón [orcid.org/0000-0002-9401-1741] es catedrático de Historia e Instituciones Económicas en la Universidad de Almería. Dirección para correspondencia: Departamento de Economía y Empresa, Facultad de Ciencias Económicas y Empresariales, Universidad de Almeria, Ctra. Sacramento, s/n, 04120 La Cañada de San Urbano (Almería, España).C.e.: aspicon@ual.es

José Joaquín García Gómez [orcid.org/0000-0002-3518-786X] es profesor ayudante doctor de Historia e Instituciones Económicas en la Universidad de Almería. Dirección para correspondencia: Departamento de Economía y Empresa, Facultad de Ciencias Económicas y Empresariales, Universidad de Almería, Ctra. Sacramento, s/n,04120 La Cañada de San Urbano (Almería, España).C.e.:josejgg@ual.es 


\section{INTRODUCCIÓN ${ }^{1}$}

La política agraria durante el primer franquismo optó por desarrollar una contrarreforma técnica que la distanciara del contenido primordialmente social y redistributivo que había sostenido el programa de reforma agraria durante la Segunda República. La política de riegos y la política de colonización, íntimamente relacionadas, fueron los ejes que articularon la actuación del Gobierno, fundamentalmente a través del Instituto Nacional de Colonización (INC). Este organismo, creado en octubre de 1939, va a ser el instrumento de una actuación estatal cada vez más intensa, caracterizada por la orientación técnica del problema social agrario, por el fomento productivo mediante la expansión del regadío y por la transformación del medio rural (Barciela \& López Ortiz, 2000: 323-328). Sin embargo, la escasez de los recursos asignados al INC, en contraste con la ambición de sus proyectos de transformación del agro español, provocaría un balance muy pobre de realizaciones durante su primera década de existencia. Barciela (1990: 226-349) ha analizado con detalle la precariedad financiera en la que se desenvolvía el INC durante los años cuarenta, lo que le llevaría, dada la parquedad de las asignaciones presupuestarias, a realizar emisiones de deuda pública y obligaciones como vía primordial para allegar recursos hasta los años cincuenta. No obstante, el INC se desenvolvió en los cuarenta siempre carente de una planificación adecuada y con una actuación caracterizada por elevadas dosis de improvisación.

El contexto económico general no era en absoluto favorable. Por otro lado, las decisiones de política económica no ayudarían a una rápida recuperación de la economía española durante la posguerra. La serie del producto interior bruto elaborada por Prados de la Escosura (2003: 160) insiste en señalar la debilidad de la recuperación en la segunda mitad de los cuarenta, con una tasa de crecimiento de apenas el 2,4\% entre 1944 y 1952, muy baja en el contexto europeo de posguerra. Las dificultades de los años siguientes a la finalización de la Segunda Guerra Mundial estarían determinadas por el aislamiento internacional, que castigaría al régimen franquista y que se plasmaría en la exclusión de España de las naciones que se vieron beneficiadas por el Plan Marshall (Álvaro, 2011: 78). Por el contrario, la misma serie pone de relieve una importante aceleración durante los años cincuenta. Entre 1952 y 1958 se alcanzaría una tasa del 4,4\%, un $80 \%$ por encima de la anotada en el periodo anterior. En resumen, se trata de un evidente cambio de trayectoria desde 1951 que inauguraría una fase excepcional de crecimiento acelerado, que terminaría enlazando, superada la contracción de 1959, con los años sesenta, la década desarrollista por excelencia (Prados de la Escosura, 2003: 162-163).

1. ¡España se prepara! es el título de un documental propagandístico del Instituto Nacional de Colonización, dirigido por Francisco González de la Riva y Vidiella, marqués de Villa Alcázar, en 1949 (Ministerio de Medio Ambiente y Medio Rural y Marino, 2008). 
Del mismo modo que la exclusión de los programas de ayuda norteamericana en la segunda mitad de los cuarenta debió penalizar la recuperación económica, cabe suponer que el crecimiento de los cincuenta pudo tener algo que ver con la superación del aislamiento exterior, como consecuencia del nuevo papel que pasa a jugar España en el panorama geopolítico internacional y con la apertura, aunque fuera tardía en el contexto europeo, de algunas líneas de ayuda económica desde los Estados Unidos. Recientemente, Maluquer de Motes (2014: 286-289) ha destacado el importante papel de ese «maná americano» en la recuperación económica española de los cincuenta.

Además, este cambio de ciclo se vio acompañado por una nueva definición de la política agraria y del desarrollo de los programas de colonización, en los que la influencia de las experiencias norteamericanas ganaría peso. Mientras que la ley de bases de 26 de diciembre de 1939 para la colonización de grandes zonas se había inspirado en la legislación italiana de la bonifica integrale, la ley de 21 de abril de 1949 sobre colonización y distribución de la propiedad en grandes zonas regables, encuentra un sólido apoyo en la experiencia norteamericana (Mangas, 1990: XXXI).

A partir del informe Kennan de 1947 se fue abriendo una nueva visión en el Gobierno norteamericano respecto de la colaboración con el español. Para el Gobierno estadounidense, el desarrollo económico de países como España pasaba a comienzos de los cincuenta por aumentar la inversión, incrementar el comercio exterior con el bloque occidental, mejorar la relación gobierno-sociedad y propiciar el intercambio de conocimiento entre las naciones. Según su criterio, la estrategia de la industrialización acelerada de los cuarenta era responsable de los importantes desequilibrios macroeconómicos que se padecieron y errónea al no ir precedida, o al menos simultanearse, de la modernización del sector agrario (Álvaro, 2011: 87-88).

Aunque no existe un consenso claro entre los historiadores económicos del grado de transcendencia que la ayuda americana representó en su conjunto para la economía española de los años cincuenta, lo que sí parece evidente es que permitió un aumento muy significativo de las importaciones españolas y, sobre todo, que este se produjo en sectores en los que la oferta interior era bastante reducida ${ }^{2}$.

2. Clavera et al. (1976: 254-255) destacaron hace ya tiempo el papel de la ayuda americana en el crecimiento de los cincuenta. En el caso del sector agrario y la financiación del INC, BARCIELA y LÓPEZ (2000: 327-328) incluyen su papel entre las aportaciones que van a permitir liberar al INC de la dependencia exclusiva de la emisión de deuda pública y obligaciones. Calvo (2001) es más escéptico respecto de su importancia, mientras que MALUQUER DE MOTES (2014: 285-289) la reivindica y la destaca. 
Muy pronto se activaron los contactos relacionados con acciones en el ámbito de la modernización agraria. En mayo de 1947 tuvo lugar el viaje del subdirector de Explotación del INC, Ángel Martínez Borque, a conocer la labor llevada a cabo por la Administración norteamericana en la colonización de los regadíos del oeste de los Estados Unidos, en concreto para estudiar los métodos y maquinaria empleados en las obras de transformación de las tierras para riego a gran escala y ampliar datos referentes a su legislación de regadíos, su aplicación práctica y la organización de las entidades encargadas de desarrollarlas (Martínez Borque, 1948: 9). Sería este modelo de colonización americano, basado en la generación de plusvalías por las obras hidráulicas y en la parcelación y colonización de las "tierras en exceso», el que posteriormente se pretendería poner en práctica con la ley de 21 de abril de 1949 sobre colonización y distribución de la propiedad en zonas regables. Esta nueva ley se centró exclusivamente en las colonizaciones de alto interés nacional de las grandes zonas regables dominadas por las obras hidráulicas construidas o auxiliadas por el Estado, lo que deja claro el giro que se pretendía dar a la fracasada política de colonización emprendida tras la aprobación de la ley de bases para colonización de grandes zonas de 1939. Además, subordinaba la extensión y el contenido de la relación dominical de los propietarios al cumplimiento de fines sociales de rango superior, lo que posibilitaba la expropiación forzosa por el Estado de las tierras declaradas en exceso por los planes generales de colonización ${ }^{3}$.

Tras este primer contacto, la intensificación de la guerra fría a partir del estallido del conflicto de Corea en 1950 favorecería la cooperación con el régimen español, una vez que la Península se confirmaba como un enclave estratégico de primer orden para el Gobierno norteamericano. Aunque ya en 1949 España había recibido un crédito de 25 millones de dólares (en lo sucesivo $\mathrm{M} \$$ ) del National City Bank norteamericano para la compra de alimentos (Barciela, 2002: 358), septiembre de 1950 marcaría un hito en la historia de la ayuda norteamericana, al promulgar el presidente Truman la ley general de asignaciones de 1951 en la que se concedía a España la posibilidad de acceder a un préstamo de 62,5 M\$ a través del Export Import Bank (Eximbank), en parte gracias a la defensa a ultranza de los intereses españoles llevada a cabo por el senador Patrick McCarran (Viñas, 2003: 78-83). Los préstamos del Eximbank se destinaron principalmente a la adquisición de maquinaria y bienes de consumo para la industria y la agricultura (ibid.: 292).

El malestar social (Clavera et al., 1976: 214) y las opiniones existentes dentro del propio régimen favorables a un cambio de rumbo se vieron reflejados en la renovación casi total del Gobierno en 1951, en el que se nombraron ministros críticos con la política autárquica seguida y partidarios de introducir reformas de signo liberalizador en la econo-

3.Boletín Oficial del Estado (BOE), núm. 112, 21/04/1949, pp. 1.806-1.809. 
mía española, como Arburúa en Comercio, Gómez de Llano en Hacienda o Cavestany en Agricultura (Barciela, 2012). A pesar de que existían razones objetivas que desde hacía muchos años justificaban este giro, no se debe pasar por alto que estas reformas liberalizadoras de la economía española pudieran responder tanto a motivaciones de tipo endógeno como a las exigencias de los Estados Unidos de que los países beneficiarios de su ayuda económica adoptasen los principios fundamentales de su modelo capitalista. Aunque es difícil precisar la incidencia exacta de cada uno de los acontecimientos, sí se ha atribuido un papel decisivo a Rafael Cavestany al frente del Ministerio de Agricultura en el viraje de la política agraria durante sus mandatos. Líneas esenciales de la nueva etapa serían: el fin de la política intervencionista y la elevación de los precios de tasa; el incremento de la producción y la productividad; las eficaces políticas de colonización, repoblación forestal y concentración parcelaria; la mejora de la cabaña ganadera; la industrialización rural; la protección económica, técnica por el Servicio de Extensión Agraria, jurídica y política para el campo; y la mejora social del campesinado (Barciela, 1986: 416420).

Con la llegada de Eisenhower a la presidencia de Estados Unidos y la firma en septiembre de 1953 de los Pactos de Madrid, las relaciones entre los dos países se intensificarían (Delgado, 2003: 245). A cambio de la construcción y utilización de las bases militares, España se benefició dentro de la ley de ayuda para la mutua defensa americana de 1949 de los programas de ayuda militar, de la ayuda económica para la defensa, de la asistencia técnica y de las compras de material en el extranjero (Baldrich, 1957: 27-29).

Para Puig (2003: 111), la ayuda económica norteamericana puede abordarse como un fenómeno bastante más amplio que los programas en los que se concretó y como un capítulo esencial de la historia económica y social de España. Pero Delgado (2003: 255) menciona la inexistencia de estudios monográficos que hayan abordado la repercusión de la ayuda americana en los diferentes sectores productivos españoles.

Nuestra investigación se ha centrado en el intento de dar respuesta a la siguiente pregunta: ¿qué trascendencia tuvo la ayuda americana a España en la modernización y colonización agraria de los años cincuenta y en especial en la labor encomendada al INC? La explotación de una documentación inédita hasta la fecha es la base de este trabajo. Estos fondos de difícil consulta del INC, por no encontrarse inventariados y estar muy restringido el tiempo disponible de acceso a ellos, se encuentran depositados en el Archivo Central del Área de Agricultura y Alimentación del Ministerio de Agricultura, Pesca y Alimentación (en lo sucesivo, ACAAA), concretamente en los almacenes del Centro Nacional de Capacitación Agraria de San Fernando de Henares. 


\section{UNA AYUDA A LA AMERICANA}

La ayuda económica para la defensa se materializaría con la Public Law 665 (PL665) y la Public Law 778 (PL778), conocida como enmienda McCarran. Además de estas ayudas enmarcadas dentro de la ley de ayuda para la mutua defensa americana de 1949, España se benefició hasta el año fiscal $1962-1963^{4}$ : a) de los créditos del National City Bank, del Export Import Bank (Eximbank) y del Development Loan Fund para la compra de bienes de consumo y productos industriales; b) desde 1955, de la compra de excedentes agrícolas americanos ${ }^{5}$, a través del título I (Sales for Foreign Currency) de la Public Law 480 (PL480), lo que generó en este caso contrapartidas (DeBlois, 1967: 8-9); y c) también en virtud de la PL480, en esta ocasión de su título II (Famine and Other Emergency Relief) y de su título III (Foreign Donations and barter), se recibieron ayudas en forma de donaciones de excedentes agrícolas o ayudas sociales de organismos intergubernamentales y organizaciones de voluntariado norteamericanas de socorro (ibid.: 2, 9-13), como fue el caso de la National Catholic Welfare Conference ${ }^{6}$.

Aunque no existe un consenso en la concreción del importe total de la ayuda económica americana recibida hasta $1963^{7}$ en concepto de asistencia técnica y para la importación de materias primas, bienes de capital y productos de consumo, según estimaciones en Calvo (2001: 257-259), la ayuda económica autorizada a España por los Estados Unidos habría alcanzado los $1.463 \mathrm{M} \$$, sin incluir la ayuda militar, habiéndose realmente desembolsado 1.361 M\$. Maluquer (2014: 286) ha cifrado en unos $1.100 \mathrm{M} \$$ el montante de los programas de asistencia norteamericana en el periodo 1951-1959.

La ayuda americana consistió en el impulso a la economía española a través de un mecanismo de coinversión similar al utilizado en el Plan Marshall (Zamagni, 2011:221-222). Si nos centramos en las ayudas asociadas a la PL665, a la PL778 (enmienda McCarran) y en la procedente del título I de la PL480, que representaron el $71 \%$ del total de la ayuda finalmente desembolsada por los Estados Unidos ${ }^{8}$, es importante señalar que no fueron

4. Véanse BALDRICH (1957: 30-31); CALVo (2001: 259); Delgado (2003: 256-259); LARRÚ (2009: 103-104); SHEARER (1959: 989-991); DeBloIS (1967: 97); y VIÑAS (2003: 288-291).

5. Antes, en 1953, se llevó a cabo la llamada Operación Trigo por valor de $20 \mathrm{M} \$$ a través de la Commodity Credit Corporation (BALDRICH, 1957: 31).

6. Repartidos en España a través de Cáritas (Delgado, 2003: 256; SHEARER, 1959: 991). Para saber más sobre la PL480, véase Díaz BERENGUER (1982).

7. Véase el análisis de las discrepancias incluido en Delgado (2003: 256-258).

8. Elaboración propia a partir de CALvo (2001: 259). El desembolso relacionado con la ayuda económica para la defensa (PL665 y PL778) entre 1954-1963 ascendió a 503,3 M\$ y con el título I de la PL480 entre 1956-1962 a 462,6 M\$, que generaron contrapartidas. 
fondos puestos a libre disposición de España, ni un préstamo, ni una donación, ya que realmente eran una disposición de dólares que se concedían para que pudieran efectuarse las importaciones desde España fijadas dentro de los programas de ayudas acordados por los dos gobiernos. Este dinero era abonado con su contravalor en pesetas ${ }^{9}$ por las empresas o instituciones públicas beneficiarias de las importaciones al Instituto Español de Moneda Extranjera, que posteriormente las depositaba en una cuenta especial del Gobierno en el Banco de España. Estas cantidades, conocidas como contrapartidas, eran gastadas en parte por el Gobierno americano (en sus bases militares, personal de la misión, etc.), que donaba o prestaba al español el resto para inversiones y gastos finalistas. Además, comprometían al Gobierno de España a coinvertir cantidades adicionales en partidas previamente acordadas, apalancando así a la economía nacional. Mediante órdenes conjuntas de los ministerios de Comercio y Hacienda se fijaron los procedimientos a seguir por las instituciones públicas para el pago del contravalor en la cuenta especial, así como de la tramitación para el empleo de los fondos de la contrapartida ${ }^{10}$.

En la Tabla 1 se presenta el reparto de las contrapartidas generadas por las Public Laws (en lo sucesivo PL) de la ayuda americana autorizadas entre 1954 y 1962, lo que permite estimar que en ese periodo quedarían a disposición de España más de $600 \mathrm{M} \${ }^{11}$. Además de los beneficios propios de las inversiones que se llevaron a cabo con ellas, no se debe obviar que dieron también lugar a saldos que actuaban como elemento estabilizador o antiinflacionista, ya que su utilización efectiva siempre se producía con cierto retraso y los remanentes se acumulaban en el Banco de España (Clavera et al., 1976: 367). El dinero a disposición de España debía ser destinado por imposición de los Estados Unidos a programas que fomentaran el desarrollo económico general del país que debían ser aprobados previamente por las autoridades americanas.

Las contrapartidas de la PL778 (enmienda McCarran) y la PL480 fueron destinadas en una proporción muy elevada a la mejora del sector agrícola (Shearer, 1959: 999). Como se demostrará, estas contrapartidas permitieron al Gobierno español acelerar sus planes

9. Según BALDRICH (1957: 29, 37-39), el contravalor dólar-peseta adoptó valores a mediados de los cincuenta de 35 ptas/\$ para la PL665 y 38,95 ptas/\$ para la PL480 y la PL778. Según Díaz (1982: 327), desde 1957 la PL665 pasó a 42 ptas/\$ y desde 1959 a 60 ptas/\$; y la PL480 desde 1958 a 42 ptas/\$ y desde 1960 a $60 \mathrm{ptas} / \$$.

10. Órdenes conjuntas de los ministerios de Comercio y Hacienda de 26/04/1955 y 24/05/1956. ACAAA, Ayuda americana, Convenios y pagos, L480, Carta de la Secretaría General Técnica del Ministerio de Agricultura a la Dirección General de Colonización, 13/06/1956.

11. Elaboración propia a partir de CALvo (2001: 259) y la Tabla 1. Se ha estimado que las contrapartidas ligadas a la PL665 rondarían los 223 M\$, a la PL778 los 44 M\$ y a la PL480 los 334 M\$. Estimaciones próximas a las de Díaz (1982: 327). 
de inversión en la expansión del regadío, que con anterioridad no habían dispuesto de los recursos económicos necesarios.

\section{TABLA 1}

Reparto de las contrapartidas generadas por la ayuda americana

\begin{tabular}{|c|c|c|c|c|c|}
\hline \multicolumn{2}{|c|}{ Public Law } & $\begin{array}{l}\text { Gastos misión del } \\
\text { Gobierno de EE.UU. } \\
\text { en España } \\
\end{array}$ & \multirow[t]{2}{*}{$\begin{array}{c}\text { Gastos de construcción y } \\
\text { mantenimiento de } \\
\text { las bases militares } \\
\end{array}$} & \multicolumn{2}{|c|}{$\begin{array}{l}\text { A disposición del } \\
\text { Gobierno español }\end{array}$} \\
\hline & & & & Donación & $\begin{array}{c}\text { Préstamo } 40 \text { años } \\
\qquad / 3 \%-4 \%^{*}\end{array}$ \\
\hline \multirow[t]{2}{*}{ PL665 } & 1954-1958 & $10 \%$ & $60 \%$ & $30,00 \%$ & - \\
\hline & 1958-1962 & $10 \%$ & - & $90,00 \%$ & - \\
\hline PL778 o enmienda & $1954-1955$ & $20 \%$ & - & $43,63 \%$ & $36,36 \%$ \\
\hline \multicolumn{6}{|l|}{ McCarran } \\
\hline \multirow[t]{8}{*}{ PL480 } & 1955 (Acuerdo 1. $^{\circ}$ & $50 \%$ & - & - & $50,00 \%$ \\
\hline & y su enmienda 1.a.) & & & & \\
\hline & 1956 (Enmienda 1. ${ }^{\mathrm{a}}$ & $40 \%$ & - & - & $60,00 \%$ \\
\hline & al $1 .^{\circ}$, acuerdo $2 .^{\circ}$ & & & & \\
\hline & y sus enmiendas $1 .^{a}$ & & & & \\
\hline & $2 .^{a}, 3 .^{a}$ y $\left.4 .^{a}\right)$ & & & & \\
\hline & 1956 (A partir & $30 \%$ & - & - & $70,00 \%$ \\
\hline & del acuerdo 3.”) & & & & \\
\hline
\end{tabular}

* Un 3\% si la devolución se producía en dólares y un 4\% si se hacía en pesetas (Díaz, 1982: 328).

Fuente: elaboración propia a partir de Baldrich (1957: 31, 37-39), Delgado (2003: 246-247) y Shearer (1959: 999).

Las contrapartidas de la PL778 (enmienda McCarran) y la PL480 fueron destinadas en una proporción muy elevada a la mejora del sector agrícola (Shearer, 1959: 999). Como se demostrará, estas contrapartidas permitieron al Gobierno español acelerar sus planes de inversión en la expansión del regadío, que con anterioridad no habían dispuesto de los recursos económicos necesarios.

\section{LA INTERVENCIÓN DEL «SENADOR POR MADRID» MCCARRANY LAS TRANSFERENCIAS POR CONTRAPARTIDAS AL INC}

En el año fiscal 1953-1954 los Estados Unidos concedieron a España con cargo a la PL665 un total de $85 \mathrm{M} \$$. Ante la reducción de esta ayuda a $30 \mathrm{M} \$$ para el año fiscal 1954-1955 y para compensarla, el lobby español en Washington encabezado por Patrick 
Anthony McCarran ${ }^{12}$ lograría la aprobación por el Senado norteamericano de la PL778, conocida como enmienda McCarran ${ }^{13}$. Los $55 \mathrm{M} \$\left(2.141,25 \mathrm{Mptas}^{14}\right.$ con el cambio considerado en el acuerdo de 38,95 pesetas/dólar) de esta nueva ayuda fueron destinados a la compra por parte de España de excedentes de productos agrícolas norteamericanos, lo que generó una contrapartida que fue asignada de la siguiente forma: un $20 \%$ a disposición de los Estados Unidos para hacer frente a sus gastos en España (11 M\$428,45 Mptas); un 36,36\% como préstamo al Gobierno español a cuarenta años a un 3\% de interés (19,998 M\$-779 Mptas); y un 43,63\% como donación al Gobierno español (23,997 M\$-934,8 Mptas). Los fondos puestos a disposición de España de esta contrapartida alcanzaron el $80 \%$ del total (44 M\$-1.713,8 Mptas). Como se verá más adelante, a pesar de tratarse de un crédito y una donación en manos del Estado español, llama la atención el estricto control de su destino por parte de la International Cooperation Administration (en lo sucesivo ICA) de los Estados Unidos ${ }^{15}$.

Estos $44 \mathrm{M} \$$ fueron empleados en el fortalecimiento del potencial económico de España, y el programa elaborado por la Dirección General de Cooperación Económica del Ministerio de Comercio los desglosó del siguiente modo: 100 Mptas para repoblación forestal, 25 Mptas para concentración parcelaria, 599,8 Mptas para colonización y regadíos, 789 Mptas para obras hidráulicas, 100 Mptas para enlaces ferroviarios y 100 Mptas para asistencia técnica (Baldrich, 1957: 41). Por tanto, a inversiones públicas directas en agricultura (concentración parcelaria, colonización, regadíos y obras hidráulicas) con cargo a la contrapartida de la enmienda McCarran se destinaron un total de 36,3 M\$ (1.414 Mptas), gestionados por el Ministerio de Obras Públicas y el Ministerio de Agricultura, este último a través del INC. Dado que las inversiones de estos organismos ascendieron en agricultura en 1953 y 1954 a 1.603 y 1.954 Mptas, respectivamente ${ }^{16}$, es manifiesta la importancia que la aprobación de la contrapartida de la enmienda McCarran supondría para el desarrollo del programa colonizador en aquellos años.

12. Senador por Nevada, furibundo anticomunista y activo impulsor de los acuerdos con el Gobierno español, lo que hizo que se le calificara en alguna ocasión como el senador por Madrid (YвARRA, 2004: 504).

13. Aprobada por la Cámara de Representantes el 20 de agosto de 1954 y el 3 de septiembre por el Senado.

14. Millones de pesetas, aquí y en lo sucesivo.

15. La ICA sustituyó en 1954 a la Foreign Operations Admnistration (en lo sucesivo, FOA), que estaba representada en España por la United States Operations Mission (en lo sucesivo, USOM). Por parte española, en octubre de 1953 se crearía la Comisión Coordinadora de Fondos de la Ayuda Económica y en abril de 1954 una oficina específica para la ejecución de los convenios con Norteamérica, que dependía del Ministerio de Hacienda (DElGado, 2003: 247).

16. Elaboración propia a partir de BARCIELA (1990: 301). Solo se han considerado las inversiones del Ministerio de Obras Públicas y del INC. 
El destino definitivo en el territorio nacional de los 1.414 Mptas para el desarrollo de la agricultura de la contrapartida McCarran fue aprobado por los ministerios de Obras Públicas y de Agricultura el 2 de septiembre de $1955^{17}$ (el reparto se presenta en la Tabla 2). Para el INC, esta inyección de fondos extras finalistas para la ejecución de obras supondría contar con nuevos y significativos recursos, ya que durante el cuatrienio 19511954 las inversiones directas del INC en obras de transformación ascendieron tan solo a $801 \mathrm{Mptas}^{18}$. La necesidad de nuevas aportaciones al INC quedó justificada en el plan de inversiones urgentes del INC con cargo a la contrapartida de la ayuda americana de 28 de febrero de $1955^{19}$.

TABLA 2

\section{Distribución entre ministerios de los fondos de la PL778 destinados} a grandes zonas regables

\begin{tabular}{lccr}
\hline Actuaciones & $\begin{array}{c}\text { Ministerio de Obras } \\
\text { Públicas (Mptas) }\end{array}$ & $\begin{array}{c}\text { Ministerio de } \\
\text { Agricultura (INC)(Mptas) }\end{array}$ & $\begin{array}{c}\text { Superficie } \\
\text { dominada(ha) }\end{array}$ \\
\hline I. ZONAS REGABLES & 116,8 & 87,0 & 10.635 \\
Riegos derivados del pantano de Borbollón (Cáceres). & 120,6 & 80,5 & 8.093 \\
Riegos del Alto Aragón, tramo segundo del canal & & 146,0 & 14.637 \\
de Monegros (Huesca). & 294,2 & - & 17.200 \\
Canal de las Bardenas, primera zona-primera parte (Zaragoza). & 215,4 & - & 3.000 \\
Riegos derivados del pantano de Rosarito (Cáceres y Toledo). & 42,0 & 10,5 & 1.073 \\
Riegos en Valmuel (Teruel). & - & 6,0 & 639 \\
Elevaciones del Tormes (Salamanca). & - & 330,0 & 55.277 \\
Zona de Águeda, margen derecha (Salamanca). & 789,0 & 96,8 & 30.000 \\
Subtotal & - & 100,0 & \\
\hline II. NIVELACIÓN DE TIERRAS EN ZONAS DE COLONIZACIÓN & - & 73,0 & - \\
CON REDES DE RIEGO CONSTRUIDAS & - & 25,0 & - \\
\hline III. PEQUEÑOS REGADÍOS DISEMINADOS & - & $\mathbf{6 2 4 , 8}$ & $\mathbf{9 0 . 2 7 7}$ \\
\hline IV. TRASLADOS DE FAMILIAS AFECTADAS POR EXPROPIACIONES & $\mathbf{7 8 9 , 0}$ & & \\
\hline V. CONCENTRACIÓN PARCELARIA & & & \\
\hline Total & &
\end{tabular}

Fuente: ACAAA, Ayuda americana, Enmienda McCarran, Carta del subsecretario del Ministerio de Obras Públicas al director general de Cooperación Económica, 07/09/1956.

17. ACAAA, Ayuda americana, Enmienda McCarran, Carta del subsecretario del Ministerio de Obras Públicas al director general de Cooperación Económica, 07/09/1956.

18. ACAAA, Información técnica del INC, Proyecto de compra de maquinaria para nivelación de terrenos con cargo al fondo de préstamos de desarrollo económico de la ley de Seguridades Mutuas del Gobierno norteamericano, 1957.

19. ACAAA, Ayuda americana, Enmienda McCarran, Plan de inversiones urgentes del INC con cargo a las contrapartidas de la ayuda americana, 28/02/1955, p. 1 (en lo sucesivo, Plan de inversiones). 
Fruto del acuerdo de los dos ministerios, a mediados de septiembre de 1955 el INC elabora un informe adicional ${ }^{20}$ al plan de inversiones urgentes de febrero de ese año. Posteriormente, el 21 de diciembre de 1955, se elaboró un segundo informe adicional ${ }^{21}$ al plan de inversiones. Se trató de un informe con mucho mayor grado de detalle con respecto a los anteriores en el que: a) se definió por primera vez el destino pormenorizado de las inversiones por actuaciones; b) se subdividió el concepto zonas regables en obras de puesta en riego y en trabajos de nivelación; c) se subdividió el concepto pequeños regadíos diseminados en obras de puesta en riego y en perforaciones profundas; d) se definió el periodo de desarrollo del plan, que abarcaría finalmente desde el 1 de julio de 1955 hasta el 30 de junio de 1958; e) se detalló la previsión de la distribución trimestral de las inversiones; y f) se fijó la previsión para cada una de las actividades del plan por tipo de gasto (mano de obra, organización y personal técnico, materiales y varios). El elevado control que la Administración americana ejercía sobre el destino y el desarrollo de las inversiones justificó con toda seguridad la elaboración de este segundo informe adicional, previo al acuerdo bilateral posterior.

Basándose en el contenido de este segundo informe adicional, el 4 de abril de 1956 se firmaba el acuerdo núm. 9 del proyecto 52-12-053 relativo a la utilización de las pesetas procedentes de la contrapartida de la enmienda McCarran en un proyecto de colonización y regadíos entre la Dirección General de Cooperación Económica del Ministerio de Comercio y la ICA de los Estados Unidos ${ }^{22}$. En este acuerdo se incluyó definitivamente una contribución al INC con cargo a la ayuda americana de 599,8 Mptas $(15,4 \mathrm{M} \$)$ a invertir en tres años, con comienzo del plazo el 1 de julio de 1955. También en este acuerdo se inclúa el compromiso del Estado español de destinar en paralelo $2.703,4$ Mptas $(69,4 \mathrm{M} \$)$ al programa nacional de colonización y regadíos en el mismo periodo de tres años. El apoyo de la ICA al proyecto se fundamentó en las recomendaciones incluidas en el informe de julio de 1954 de A. N. Thompson del USBR sobre el programa del INC sobre regadíos y colonización nacional, en el que estaba prevista la puesta en riego de 600.000 hectáreas y la reinstalación de 30.000 familias en seis años ${ }^{23}$.

20. ACAAA, Ayuda americana, Enmienda McCarran, Informe adicional del plan de inversiones urgentes del INC con cargo a la asignación procedente de la Enmienda McCarran, 17/09/1955.

21. ACAAA, Ayuda americana, Enmienda McCarran, Segundo informe adicional del plan de inversiones urgentes del INC con cargo a la asignación procedente de la enmienda McCarran, 21/12/1955.

22. ACAAA, Ayuda americana, Enmienda McCarran, Acuerdo relativo a la utilización de pesetas procedentes de la enmienda McCarran en un proyecto de colonización y regadíos, 04/04/1956 (en lo sucesivo, Acuerdo 04/04/1956). Se trata del proyecto 52-12-073, acuerdo núm. 9, de título Colonización y regadíos, núm. de aportación ICA 05271XUU.

23. ACAAA, Ayuda americana, Convenios y pagos, L480, Proyecto 52-12-122, Proyecto 375 Mptas, 
El acuerdo contemplaba la transformación en regadío de 37.442 hectáreas, la nivelación de 16.580 hectáreas en zonas de colonización con redes de riego -que ya se encontraban construidas- y el traslado de 516 familias. Contaba con diversas normas generales y específicas de gestión y seguimiento del proyecto, entre las que destacaba la obligación por parte del INC de remitir a la ICA informes detallados mensuales y trimestrales del desarrollo de las obras. Además, el Gobierno español daba al de los Estados Unidos la capacidad de supervisar en cualquier momento que las actividades que se realizaban se ejecutaban conforme a los fondos del acuerdo, incluyéndose en este precepto la inspección y análisis sobre el terreno de las inversiones, así como su documentación y contabilidad donde quiera que dicha documentación se encuentre o conserve ${ }^{24}$.

Las actuaciones a las que serían destinados los casi 600 Mptas se subdividieron en: zonas regables (330 Mptas); nivelación de tierras en zonas de colonización con redes de riego construidas (96,8 Mptas); pequeños regadíos diseminados (100 Mptas); y traslado de familias $(73 \mathrm{Mptas})^{25}$. Aunque la firma del acuerdo para el destino de los fondos tuvo lugar en abril de 1956, en el primer informe con la justificación de las obras ejecutadas remitido a la ICA se incluyeron trabajos acometidos desde el 1 de julio de $1955^{26}$.

En el epígrafe Zonas regables se incluyeron las ejecutadas a través de los planes coordinados de obras gestionados por el INC y los Servicios Hidráulicos del Ministerio de Obras Públicas, recogidas todas en el Plan de Obras Públicas de $1939^{27}$. En estas cinco zonas a las que se destinaron los fondos (pantano de Borbollón, canal de Monegros, canal de las Bardenas, pantano de Santa Teresa-Tormes y pantano de Águeda) estaban ya finalizadas, o a punto de terminarse, las grandes infraestructuras de regulación hidráulica (presas) y de transporte (canales). Las nuevas inversiones del INC se centraron en la ejecución de los canales secundarios (acequias), los sistemas de drenaje y en la preparación y nivelación de tierras.

Con relación al epígrafe Nivelación de tierras en zonas de colonización, a comienzos de 1955 el INC estimaba que existían unas 34.725 hectáreas fuera de los planes Badajoz y Jaén dominadas por redes de riego pendientes de ser niveladas, no existiendo par-

Acuerdo 56, 28/06/1956, p. 2.

24. ACAAA, Ayuda americana, Enmienda McCarran, Acuerdo 04/04/1956, Anejo A, Normas Generales.

25. ACAAA, Ayuda americana, Enmienda McCarran, Acuerdo 04/04/1956.

26. ACAAA, Ayuda americana, Enmienda McCarran, Carta del director general del INC al director general de Cooperación Económica, 23/07/1956.

27. BOE, núm. 115, 25/04/1939, pp. 2.238-2.239. 
tida en el presupuesto de ese año para ese concepto ${ }^{28}$. Una vez niveladas y preparadas estas tierras, se habría estado en disposición de ponerlas en regadío y proceder a la instalación de colonos. Este programa de nivelación se vería claramente acelerado gracias a la aplicación de la contrapartida McCarran, que pretendía actuar sobre un total de 16.580 hectáreas de zonas y fincas del INC con redes de riego ya construidas.

El tercer grupo de actuaciones, Pequeños regadios diseminados, se relacionaba con pequeños regadíos dispersos por toda España en los que el riego no se realizaría con aguas de pantanos. Se pretendió la puesta en regadío de 3.903 hectáreas de zonas y fincas del INC mediante la ejecución de pozos excavados y galerías, instalación de bombas de elevación en pozos y ríos, electrificaciones, redes de riego y caminos.

El último grupo de actuaciones contemplado, Traslado de familias, fue la reubicación de algunas de las familias que se vieron desplazadas de sus lugares de residencia por la inundación de las aguas reguladas en las nuevas presas. Además, se tuvo en cuenta el realojo de las familias desplazadas a consecuencia de la construcción de la base naval de Rota (Cádiz).

El 30 de junio de 1958, tras tres años de trabajos, finalizaron las actuaciones incluidas en el acuerdo de la contrapartida McCarran. El importe total de las obras ascendió a los 599,8 Mptas disponibles, no coincidiendo el reparto final dentro de los distintos epígrafes con las previsiones recogidas en el acuerdo inicial de 4 de abril de 1956. La transformación de tierras en las grandes zonas regables fue de 33.863 hectáreas y en la nivelación de zonas del INC con redes de riego de 11.687 hectáreas, sin especificarse para los pequeños regadíos diseminados (véase Tabla 1 del anexo documental).

\section{CONTRAPARTIDAS DE LA PL480}

Durante la década de los cincuenta también se destinó a la colonización agrícola dinero de las contrapartidas generadas por la PL480, en concepto de préstamo de los Estados Unidos a España al 3\% de interés y a cuarenta años. En concreto, 475 Mptas procedieron de los ingresos en pesetas del pago de los excedentes agrícolas que llegaron a España con la PL480 en $1956^{29}$ y 1.000 Mptas de los que lo hicieron en $1959^{30}$. Los primeros

28. ACAAA, Ayuda americana, Enmienda McCarran, Plan de inversiones, pp. 5-6.

29. Acuerdo firmado el 06/12/1955. ACAAA, Ayuda americana, Convenios y pagos, L480, Pequeños regadíos, Proyecto 52-12-121, Proyecto 100 Mptas, p. 5.

30. Acuerdo firmado el 05/11/1957. ACAAA, Ayuda americana, Convenios y pagos, Plan de inver- 
475 Mptas coincidieron parcialmente en el tiempo con la contrapartida de la enmienda McCarran, aunque comenzaron un año después, en el verano de 1956. Se trataba de una financiación adicional para los proyectos incluidos en los acuerdos de la contrapartida McCarran.

En febrero de 1956 se aprobaba un nuevo plan de inversiones del INC para grandes zonas regables, formulado tras un acuerdo con el Ministerio de Obras Públicas para el reparto de $1.150 \mathrm{Mptas}$ de la contrapartida de la PL480 ${ }^{31}$. El reparto de inversiones entre los ministerios de Obras Públicas y Agricultura se desglosa en la Tabla 3, encargándose Obras Públicas de las grandes obras hidráulicas (presas, redes principales y encauzamientos) y Agricultura a través del INC de las redes secundarias, elevaciones, trabajos de nivelación, saneamiento y caminos.

El empleo de estos 375 Mptas quedó definido dentro del proyecto 52-12-122 titulado Regadíos y colonización, firmado el 28 de junio de 1956, en el que se recogía la obligación del Estado español de dedicar a los mismos fines un total de 562,1 Mptas con cargo a los presupuestos del INC de 1956-1957. Con este proyecto se buscaba la puesta en riego de otras 52.575 hectáreas $^{32}$ y tuvo la singularidad de que su aprobación no incluyó la preceptiva firma de los Project agreements, lo que hizo que el INC a pesar de haber comenzado las obras en el verano de 1956 no pudiera contar con los fondos del préstamo para hacer frente a los gastos generados. No sería hasta el 30 de enero de 1959 cuando se firmaran los Project agreements, conjuntamente con una modificación que dio lugar al acuerdo 56 del proyecto 52-12-122. En esta modificación la superficie que se tenía previsto poner en riego aumentó hasta las 59.395 hectáreas $^{33}$. La falta de libramientos de los fondos de la contrapartida para el pago de los gastos generados por estas obras, que llegaron a alcanzar los $325 \mathrm{Mptas}$ en enero de 1959, provocó un desequilibrio económico en las cuentas del INC, que sería responsable en parte de los problemas presupuestarios que sufriría el organismo a finales de los cincuenta ${ }^{34}$, además de casi provocar que se de-

siones a cargo de LP480, ICA 10-5/Proyecto 52-12-228, Proyecto 1.000 Mptas, Acuerdo 112, 30/07/1959.

31. La falta de coordinación técnica entre los ministerios de Obras Públicas y de Agricultura fue señalada a comienzos de 1957 como uno de los impedimentos que lastraban la labor colonizadora. ACAAA, Régimen económico del INC, Antecedentes I, Labor desarrollada por el INC y medidas convenientes para mayor eficacia de actuación, 25/03/1957. p. 9.

32. ACAAA, Ayuda americana, Convenios y pagos, L480, Proyecto 52-12-122, Proyecto 375 Mptas, 28/06/1956, pp. 1-2.

33. ACAAA, Ayuda americana, Convenios y pagos, L480, Proyecto 52-12-122, Proyecto 375 Mptas, Acuerdo 56, 28/06/1956, pp. 1-3.

34. Analizado en detalle en BARCIELA (1990: 344-349). 
cretara la paralización de todas las obras de este proyecto en el verano de $1957^{35}$. A pesar de que las previsiones marcaban el final del programa para diciembre de 1958, este finalizó en septiembre de 1959, ejecutándose actuaciones en todas las zonas previstas salvo en los riegos de Hellín (véase Tabla 2 del anexo documental).

Paralelamente al programa descrito de 375 Mptas para grandes zonas de regadío, se desarrolló otro de $100 \mathrm{Mptas}$ destinado a los denominados pequeños regadíos. En febrero de 1956 el INC formularía un plan de inversiones con cargo a la contrapartida procedente de la PL480 para estos pequeños regadíos, que al mes siguiente sería aprobado por el Consejo de Ministros. El 25 de junio de ese mismo año sería rubricado el acuerdo 29 del proyecto 52-12-121, Pequeños regadíos, por un importe de 100 Mptas de la contrapartida de la $\mathrm{PL} 480^{36}$, mientras España se comprometía a invertir paralelamente $150 \mathrm{Mptas}^{37}$. Se buscaba continuar con la labor de puesta en riego de áreas pequeñas y aisladas, que no justificaba su conexión con el sistema nacional de grandes obras hidráulicas (presas y canales). Encomendado al INC, afectaría a 13 provincias (Albacete, Cáceres, Cádiz, Ciudad Real, Cuenca, Granada, Lugo, Málaga, Palencia, Salamanca, Segovia, Sevilla y Toledo) con el objetivo de transformar más de 11.400 hectáreas gracias al desvío de corrientes, la construcción de pequeñas balsas, embalses y sistemas de distribución, y para trabajos de investigación y captación de aguas subterráneas ${ }^{38}$. Durante el desarrollo del proyecto se aprobaron dos revisiones del acuerdo inicial para ser adaptado a las actuaciones realmente ejecutadas, el 12 de enero de 1957 y el 28 de junio de 1957. En la segunda revisión se incluyeron nuevas actuaciones en las provincias de Almería, Alicante, Castellón y Zamora, principalmente relacionadas con la ejecución de captaciones de aguas subterráneas en las tres primeras, aunque se redujo el objetivo de transformación a poco más de 9.500 hectáreas $^{39}$. El programa quedaría finalizado en septiembre de 1958, tres meses antes de lo previsto en el acuerdo inicial y sus revisiones (véase Tabla 3 del anexo documental).

35. ACAAA, Ayuda americana, Convenios y pagos, L480, Proyecto 375 Mptas, Carta de la Dirección General de Colonización a la Dirección General del Tesoro, 03/09/1957, pp. 1-2.

36. ACAAA, Ayuda americana, Convenios y pagos, L480, Proyecto $100 \mathrm{Mptas,} \mathrm{Pequeños} \mathrm{regadíos,}$ LP480.

37. ACAAA, Ayuda americana, Convenios y pagos, L480, Proyecto 52-12-121, Proyecto 100 Mptas, Pequeños regadíos, Acuerdo 29, 25/06/1956.

38. ACAAA, Ayuda americana, Convenios y pagos, L480, Proyecto 52-12-121, Proyecto 100 Mptas, Pequeños regadíos, pp. 6-8.

39. ACAAA, Ayuda americana, Convenios y pagos, L480, Proyecto 52-12-121, Proyecto 100 Mptas, Pequeños regadíos, Revisión n. ${ }^{\circ}$ 2, Acuerdo 29, 25/06/1956. 


\section{TABLA 3}

Distribución entre ministerios de los fondos de la primera contrapartida de la PL480 destinada a grandes zonas regables

\begin{tabular}{|c|c|c|c|}
\hline Actuaciones & $\begin{array}{c}\text { Ministerio de Obras } \\
\text { Públicas (Mptas) }\end{array}$ & $\begin{array}{l}\text { Ministerio de Agricultura } \\
\text { (INC)(Mptas) }\end{array}$ & $\begin{array}{c}\text { Superficie } \\
\text { afectada(ha) }\end{array}$ \\
\hline \multicolumn{4}{|l|}{ GRANDES ZONAS REGABLES. } \\
\hline Regadíos del canal de las Bardenas (Zaragoza). & 150 & 180 & 100.000 \\
\hline Regadíos del canal de Monegros (Zaragoza y Huesca). & 170 & 113,5 & 54.000 \\
\hline Riegos del Bajo Guadalquivir (Sevilla). & 170 & 34 & 60.000 \\
\hline Zona regable de Guadalcacín (Cádiz). & 100 & 22,5 & 12.000 \\
\hline Saneamiento terrenos pantanosos del Guadiana, & 50 & - & 25.000 \\
\hline \multicolumn{4}{|l|}{ Cigüela y Záncara (Ciudad Real). } \\
\hline Pantano del Porma (León). & 25 & - & - \\
\hline Pantano de Guara (Huesca). & 10 & - & - \\
\hline Pantano de la Torre de Abraham (Ciudad Real). & 40 & - & - \\
\hline Pantano de Santomera (Murcia). & 20 & - & - \\
\hline Riegos de Hellín (Albacete). & - & 25 & - \\
\hline Pantano del Puerto en el río Azuer (Ciudad Real). & 10 & - & - \\
\hline Pantano en el alto Guadalimar (Jaén). & 8 & - & - \\
\hline Pantano de Riofrío (Ávila). & 4 & - & - \\
\hline Encauzamiento del río Soquillo (Valladolid). & 18 & - & - \\
\hline Total & 775 & 375 & 251.000 \\
\hline
\end{tabular}

Fuente: ACAAA, Ayuda americana, Convenios y pagos, L480, Proyecto $375 \mathrm{Mptas}$, Plan de inversiones del INC con cargo a la contrapartida LP480, pp. 2-4.

Estando aún en ejecución el proyecto núm. 52-12-122 de 375 Mptas, el 30 de julio de 1959 se firmó el acuerdo 112 de proyecto núm. 152-12-228 con una ayuda de 1.000 Mptas de la contrapartida de la PL480, con el compromiso español de la inversión de poco menos de $1.012 \mathrm{Mptas}^{40}$. Con inicio en junio de $1959 \mathrm{y}$ final en marzo de 1960 se prolongó la ejecución de las obras hasta septiembre de $1960^{41}$. Con idénticos objetivos colonizadores que las otras tres ayudas ya analizadas, perseguía transformar en regadío 38.722 hectáreas y la construcción de 2.231 viviendas para colonos ${ }^{42}$. Incluía inversio-

40. ACAAA, Ayuda americana, Convenios y pagos, Plan de inversiones a cargo de la LP480, ICA 10-5/Proyecto 52-12-228, 1.000 Mptas, Acuerdo 112, 30/07/1959, pp. 1-2.

41. ACAAA, Ayuda americana, Convenios y pagos, Plan de inversiones a cargo de la LP480, Proyecto 52-12-228, 1.000 Mptas, Informe trimestral 01/06/59 a 31/09/60, p. 1.

42. ACAAA, Ayuda americana, Convenios y pagos, Plan de inversiones a cargo de la LP480, ICA 10-5/Proy 52-12-228, 1.000 Mptas, Acuerdo 112, 30/07/1959, p. 2. 
nes en actuaciones coordinadas entre el INC y la Dirección General de Obras Hidráulicas, así como en otras exclusivas del INC en sus zonas de interés nacional, núcleos y fincas. También se prestó atención en este proyecto a la investigación de las aguas subterráneas para la transformación en regadío de zonas de diversas provincias y a la construcción de carreteras en zonas de concentración parcelaria (véase Tabla 4 del anexo documental).

Ya en la década de los sesenta y también con cargo a la ayuda americana, en forma del préstamo generado por la PL480 entre 1960 y 1963, se rubricarían otros tres acuerdos entre los Estados Unidos y España para el desarrollo agrícola de la nación a través de proyectos gestionados y ejecutados por el INC, continuando la labor desarrollada en la segunda mitad de la década de los cincuenta. Fueron los acuerdos 145, 178 y 207 del proyecto 52-12-228, con una ayuda de 2.057,6 Mptas de la contrapartida de la PL480 y un compromiso español de inversión de $2.280,7$ Mptas.

\section{NO SOLO CONTRAPARTIDAS. TRANSFERENCIA Y MODERNIZACIÓN TECNOLÓGICA}

\subsection{La mecanización de las grandes transformaciones de tierras}

A comienzos de 1955 muchas zonas y fincas del INC, a pesar de disponer de agua para su irrigación, no habían sido aún transformadas, a causa de la falta de un número suficiente de equipos mecánicos de movimiento de tierras ${ }^{43}$.Varios autores han analizado en profundidad la secular falta de mecanización de la agricultura española y su atraso respecto de otros países europeos y los Estados Unidos (Aguirre, 1956: 10; Asociación Nacional de Ingenieros Agrónomos, 1950; Garrabou, 1990; Martínez Ruiz, 2000). Además, desde 1939 la política agraria española se fundaría sobre los pilares de la autarquía y el intervencionismo. Esta opción provocaría los siguientes efectos adversos, entre otros: a) la pérdida de los mercados agrícolas internacionales; b) la reducción de las importaciones de los medios de labor agrícola, lo que provocó un retroceso en la tecnificación de la maquinaria agrícola, la escasez de medios y de piezas de recambio para los equipos en servicio; c) el establecimiento de cupos de carburantes (Barciela \& López Ortiz, 2003: 23 25); y d) dificultades de suministro de energía eléctrica. El intervencionismo en las importaciones que ejercía el Estado se basaba en el denominado régimen de licencias, cuya naturaleza de trámite administrativo individual permitía que la discrecionalidad pudiera surgir en cualquier momento del proceso. Estas licencias se concedían fijando un plazo

43. ACAAA, Ayuda americana, Enmienda McCarran, Plan de inversiones, p. 5. 
temporal y una cuantía determinada, y su tramitación era un largo camino que comprendía la solicitud al Ministerio de Industria y Comercio, la conformidad de la Dirección General de Aduanas, la publicación de la solicitud en el BOE, el trámite favorable de la Comisión Reguladora de Comercio Exterior y la publicación final de la concesión en el BOE (Clavera et al., 1976: 184-185).

A esta política interna habría que sumar las consecuencias del aislamiento internacional que sufriría España en los cuarenta. Las empresas nacionales de fabricación de maquinaria agrícola también sufrieron durante esa década restricciones en el abastecimiento de acero laminado, lo que les impidió el normal desarrollo de sus programas de fabricación y les obligó a adaptarse a los suministros concedidos por la Delegación Oficial del Estado en las Industrias Siderúrgicas (Asociación Nacional de Ingenieros Agrónomos, 1950: 46, 97-98).

Los efectos negativos de esta coyuntura sobre la disponibilidad de los medios de labor agrícolas de series de fabricación largas (motores, arados, sembradoras, abonadoras, cosechadoras, trilladoras, etc. $)^{44}$ eran aún mucho más palpables en las tipologías de maquinaria de series de fabricación cortas, como era el caso de los equipos de movimiento de tierra de tamaño medio-grande empleados en las nivelaciones de tierras acometidas por el INC, donde la dependencia internacional había sido históricamente mucho mayor. Se trataba de maquinaria comúnmente utilizada en el ámbito de la obra civil o pública.

Aunque existen referencias de la importación por parte del INC de subsoladores profundos (rippers) americanos en 1948 (Aguirre, 1956: 11), la primera gran operación de adquisición de maquinaria de movimiento de tierras la llevaría a cabo el INC en el año 1953 con cargo a los créditos del Export Import Bank (Eximbank). Se trató de 56 equipos importados de los Estados Unidos entre los que, principalmente, se encontraban bulldozers, tractores de cadenas, rippers, traíllas y motoniveladoras, propios de grandes movimientos de tierras para la nivelación de zonas regables ${ }^{45}$. Tras este primer programa de importaciones de maquinaria del INC se sucedieron otros créditos mayores durante la década de los cincuenta con cargo a la PL665 de la ayuda económica para la defensa de los Estados Unidos a España, entre los que destaca el importe consignado a tal efecto du-

44. Sobre series largas de producción de maquinaria agrícola, véase MARTíNEZ RUIZ (2000: 157200).

45. ACAAA, Subsecretaría Técnica Maquinaria, Importaciones, Antecedentes, c. 53/1, Préstamo americano, 1953. 
rante el año fiscal 1953-1954, que se materializaría en $1954^{46}$. En el Gráfico 1 se presenta la evolución entre 1953 y 1960 de la inversión anual del INC con cargo a la ayuda americana destinada a la importación de maquinaria, salvo en 1953 que se hizo con cargo al crédito, y se diferencian las inversiones en maquinaria de movimiento de tierras y la destinada a la captación de aguas subterráneas.

\section{GRÁFICO 1}

Evolución de las importaciones de maquinaria del INC en el periodo 1953-1960 con cargo al crédito (1953) y a la ayuda americana (1954-1960) en M\$

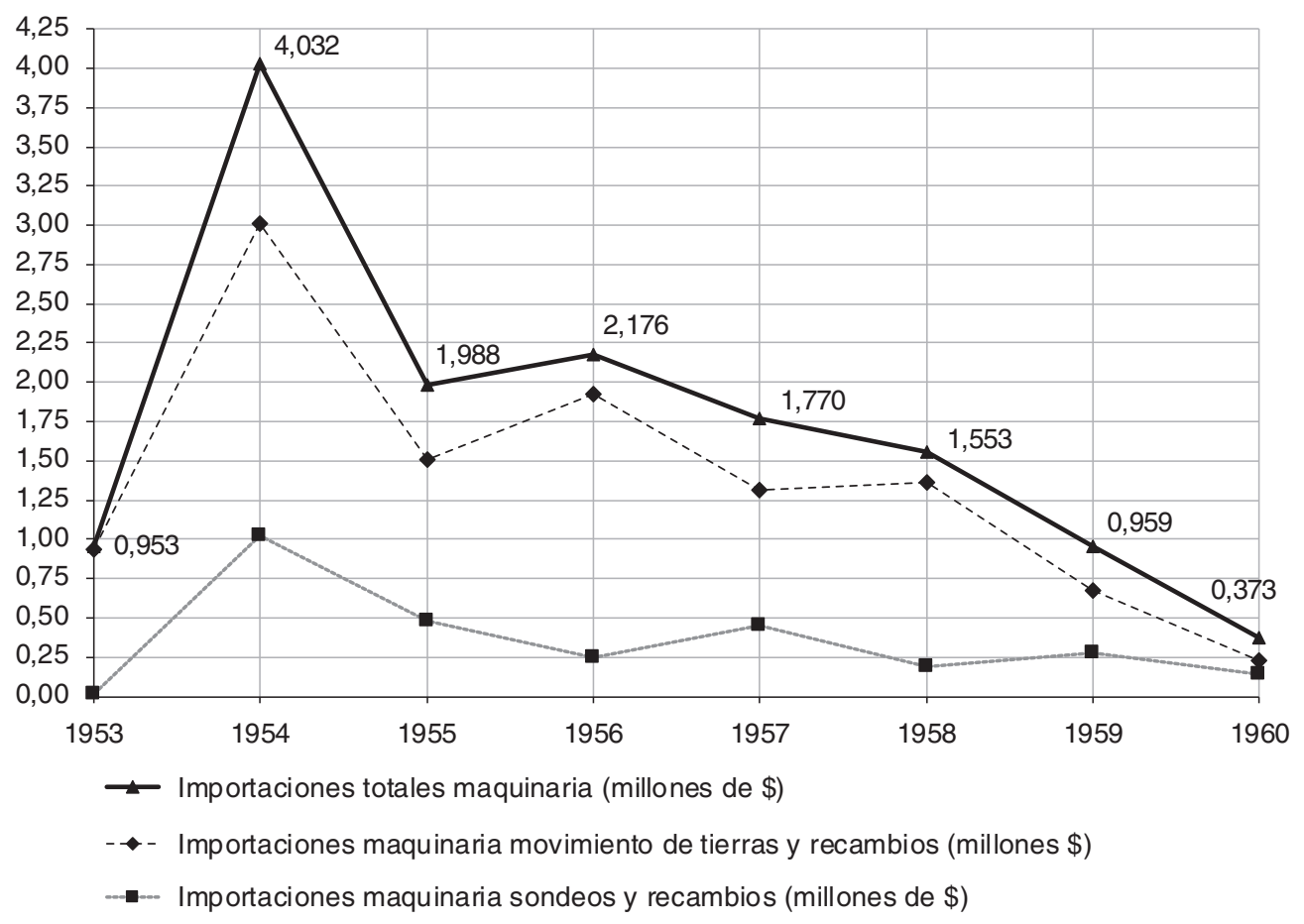

Fuente: elaboración propia a partir de ACAAA, Subsecretaría Técnica Maquinaria, Importaciones, Antecedentes, c.53/0.

Con anterioridad a 1955, las importaciones del INC procedentes de la ayuda americana fueron gestionadas a través de la FOA, pasando desde ese año a depender de la ICA. A pesar de que las bases de los concursos convocados por el Ministerio de Agricultura para la importación de la maquinaria incluían la posibilidad de que procediera de los Estados

46. Lo normal era que la maquinaria estuviera disponible al año siguiente de la adjudicación de las importaciones. En este caso la maquinaria pudo ser empleada en 1955. 
Unidos o de los países europeos incluidos en la OCDE, casi en la totalidad de los casos la maquinaria era fabricada en Norteamérica. A partir de 1956 los importadores podían proponer equipos de cualquier procedencia, aunque continuaron prevaleciendo las marcas norteamericanas.

La implementación de estos programas destinados a la importación de maquinaria con destino al INC resultó fundamental para el normal desarrollo de las actuaciones con cargo a las contrapartidas de la ayuda americana, ya que no se podían emplear sus fondos en la compra de maquinaria.

A pesar de los importantes programas de importación de maquinaria pesada llevados a cabo, en 1958 aún se consideraba que la disponibilidad de equipos mecánicos de movimiento de tierras era un importante cuello de botella para el desarrollo del programa colonizador. Algo similar a lo que sucedía con el cupo anual de 48.000 toneladas de cemento que el INC tenía asignado, ya que a comienzos de 1957 solo las obras incluidas en la ayuda americana tenían unas necesidades de 72.000 toneladas al año de cemento, una vez y media la disponibilidad de este material de construcción ${ }^{47}$.

\subsection{La ayuda americana y el salto tecnológico en el aprovechamiento de las aguas subterráneas}

Hasta 1955 fue la transformación del secano en regadío conseguida por la iniciativa privada mediante los auxilios técnicos y económicos otorgados por el INC, a través de la ley de colonización de interés local, uno de los mayores logros de la institución. Frente a las 62.671 hectáreas servidas por las redes de riego del INC a finales de 1954, se habían transformado por particulares con auxilio del INC unas 136.500 hectáreas ${ }^{48}$. Las principales ventajas que para el INC tenían los pequeños regadíos respecto de las grandes zonas regables eran permitir resolver los problemas sociales planteados sin necesidad de traslado de las familias, con el éxito político y beneficio económico que ello conllevaba, y que los resultados de puesta en riego y colonización podían lograrse en un breve espacio de tiempo por ser obras de reducida complejidad ${ }^{49}$. Todo esto motivó que las inversiones aso-

47. ACAAA, Régimen económico del INC, Antecedentes I, Labor desarrollada por el INC en zonas regables y pequeños regadíos, y medidas convenientes para conseguir mayor eficacia de actuación, 25/03/1957, pp. 4-5.

48. ACAAA, Información técnica del INC, Proyecto de compra de maquinaria para nivelación de terrenos con cargo al fondo de préstamos para el desarrollo económico de la ley de Seguridades $\mathrm{Mu}-$ tuas del Gobierno norteamericano, 1957.

49. ACAAA, Ayuda americana, Enmienda McCarran, Plan de inversiones, pp. 6-7. 
ciadas a las contrapartidas de la ayuda americana se centrarán con intensidad en los denominados pequeños regadíos. Además, con cargo a ellas, por primera vez en España se acometió por parte del Estado una campaña intensiva de ejecución de perforaciones profundas (sondeos) para la explotación de aguas subterráneas con destino al riego, que perseguía el alumbramiento de aguas capaces de irrigar 6.775 hectáreas nuevas.

Como sucedió con la importación de maquinaria para movimiento de tierras, entre 1954 y 1956 se dotó al INC de un moderno parque de maquinaria de perforación de sondeos a rotación y percusión. Estos equipos, conjuntamente con la entrada en el mercado nacional de las bombas electrosumergidas, permitieron la puesta en riego de grandes zonas, fundamentalmente, del Levante, Andalucía y La Mancha.

$\mathrm{Al}$ igual que con la maquinaria de movimiento de tierras, la situación económica de España en la década de los cuarenta y el cierre del comercio internacional impidió el acceso a las nuevas tecnologías disponibles para el empleo de las aguas subterráneas a nivel mundial. En Martínez Rodríguez (2014: 272-274, 280-281) se analiza en detalle esta situación de bloqueo tecnológico que se vivió en el aprovechamiento de las aguas subterráneas en España hasta la década de los cincuenta, momento en que comenzaron a llegar los modernos equipos de perforación norteamericanos. Aunque hay referencias de la importación de dos máquinas de perforación en el año 1953, el primer gran programa de importación desde Norteamérica tuvo lugar durante el año fiscal 1953-1954 con cargo a la PL665 (1,025 M\$). En 1960 las importaciones en maquinaria de sondeos y recambios con destino al INC realizadas con cargo a la ayuda americana superaban los 2,8 $\mathrm{M} \${ }^{50}$.

Conjuntamente con la adquisición de las perforadoras de sondeos y también con cargo a la ayuda americana, el INC importó en 1954 un total de 30 electrobombas sumergidas de las marcas alemanas KSB y Ritz ${ }^{51}$. Se trata de la primera referencia conocida de la existencia de bombas de este tipo en España. Su uso permitiría alcanzar la madurez tecnológica en los sistemas de elevación de aguas subterráneas, posibilitando explotar niveles acuíferos inaccesibles hasta entonces en España. Asimismo, esta tecnología permitiría la ejecución de sondeos con el empleo de maquinaria de perforación de diámetros aún más reducidos que para el caso de las bombas de eje vertical, usadas hasta ese momento en España.

50. Véase análisis de estas importaciones en Gráfico 1 y en MARTínEZ RodRÍGUEZ y SÁNCHEZ PicóN (2016: 11).

51. ACAAA, Subsecretaría Técnica Maquinaria, Importaciones, Antecedentes, c. 53/2. 
Estos nuevos medios tecnológicos posibilitarían a la Administración española, a través del INC, acometer solo dentro de las actuaciones sufragadas con la contrapartida de la enmienda McCarran más de 65 sondeos de captación de aguas subterráneas. En el Gráfico 2 se puede comprobar cómo en 1960 los caudales alumbrados por el INC en sondeos perforados superaban ya a los procedentes de pozos excavados y galerías. Además, se puede ver cómo la inflexión en la curva de caudales alumbrados también se produce en el año 1956, cuando entraron en servicio los equipos de perforación avanzados. Considerando un hipotético funcionamiento en continuo de los pozos y de los sondeos ejecutados hasta finales de 1959 por la maquinaria de perforación del INC, los volúmenes anuales de aguas subterráneas podrían haber alcanzado los $618 \mathrm{hm}^{3}$. Durante los años siguientes continuó la exploración y captación de aguas subterráneas de forma sistemática por parte del INC, alcanzando los $42.208 \mathrm{l} / \mathrm{s}$ los caudales alumbrados a finales de 1965 , lo que posibilitaría contar con volúmenes anuales cercanos a los $1.331 \mathrm{hm}^{3}$.

\section{GRÁFICO 2}

Caudales alumbrados acumulados en pozos-galerías y sondeos ejecutados por el INC hasta 1965

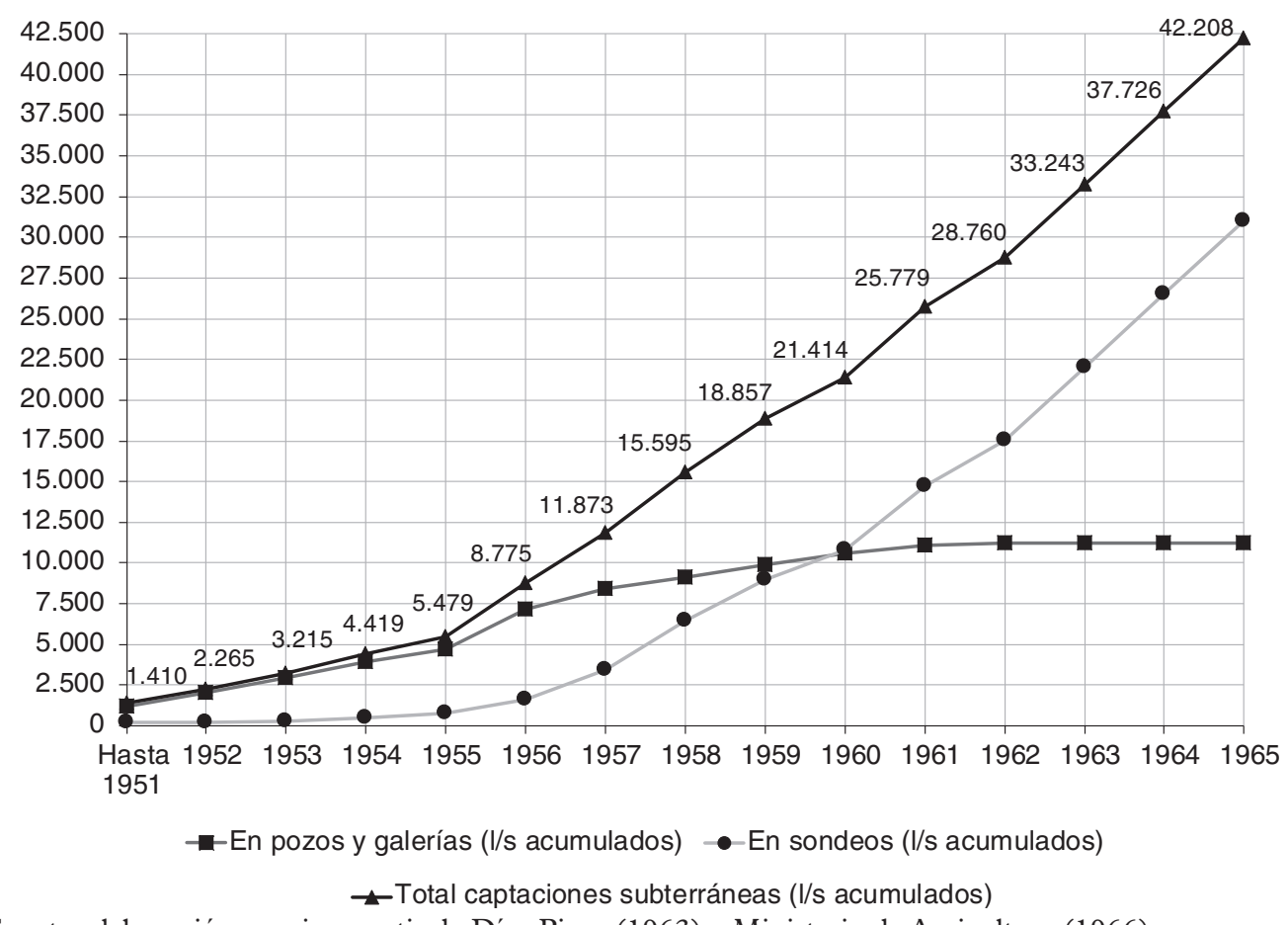

Fuente: elaboración propia a partir de Díaz Pines (1963) y Ministerio de Agricultura (1966). 


\subsection{Transferencia de conocimiento. La asistencia técnica}

Unida a todas estas iniciativas, también tuvo una gran importancia la transferencia de conocimiento procedente de los Estados Unidos. En general, todos los programas de asistencia técnica de la ayuda americana (technical exchange program) incluyeron: a) el envío de especialistas estadounidenses a España; b) las estancias de investigación en centros de formación americanos para expertos, normalmente ingenieros; y c) la organización de las llamadas misiones de productividad, en las que se trataba de formar a grupos de profesionales en cuestiones específicas de los distintos sectores, propias del modelo americano, observándolas in situ (Álvaro, 2011: 78-79). En el año 1959 se cifraban en 1.500 los profesionales técnicos que habían visitado los Estados Unidos para formarse y en 80 los expertos americanos que habían venido a España en funciones de asesoramiento, de modo que existía un intercambio continuo de técnicos de ambos países sobre todo tipo de problemas de materia agrícola (Shearer, 1959: 1001). De esta forma se dio a conocer, entre funcionarios, directivos y expertos, el paradigma tecnológico americano, subrayándose la importancia de la educación a todos los niveles y, especialmente, los logros del capitalismo (Puig, 2003: 115).

Las temáticas del programa de asistencia técnica relacionadas con el sector primario fueron gestionadas por el Ministerio de Agricultura y se encomendaron a la Comisión Nacional de Productividad Industrial (CNPI) las relacionadas con la industria y los servicios (Álvaro, 2012: 67). Al igual que existe constancia de este intercambio en cuestiones de concentración parcelaria, conservación de suelos y extensión agraria ${ }^{52}$, en el caso particular de las aguas subterráneas esta asistencia consistió en la llegada a España de especialistas norteamericanos ${ }^{53}$ y en el envío de expediciones de personal español a los Estados Unidos a conocer experiencias reales y recibir cursos de formación en el United States Geological Survey (González Asensio, 2013: 531). Además, en los primeros años de funcionamiento de las nuevas máquinas de sondeos fue habitual la integración de personal extranjero en los equipos humanos a cargo de su manejo.

\section{BALANCE DE LA AYUDA AMERICANA AL INC}

La inversión total en obras de colonización que el INC financió con cargo a las contrapartidas de la ayuda americana entre 1955 y 1963 alcanzó los 4.131,6 Mptas. Dado que

52. Gómez Benito (2007: 132-139) analiza en detalle la influencia americana en el Servicio de Extensión Agraria.

53. ACAAA, Ayuda americana, Convenios y pagos, Anexo $\mathrm{C}$ al acuerdo de la Dirección General de Cooperación Económica y la ICA, Proyecto 52-12-121, Acuerdo 29, p. 4. 
las inversiones ligadas a obras de colonización ${ }^{54}$ afrontadas por el INC en estos años alcanzaron los $11.059 \mathrm{Mptas}^{55}$, la contrapartida de la ayuda americana supuso un 37\% del total. Para este mismo periodo de tiempo y en cumplimiento de las obligaciones contraídas por el INC con la firma de los distintos acuerdos de los proyectos, el Estado español se comprometió a hacer una inversión en paralelo en obras de esta naturaleza de 6.708 Mptas. Por tanto, en relación con los acuerdos suscritos por los Estados Unidos y España debieron dedicarse a obras de colonización gestionadas por el INC un total de 10.840,4 Mptas, casi la totalidad (98\%) de lo invertido en obras de colonización para este periodo. En la Tabla 4 se presenta un resumen con los principales datos de los proyectos relacionados, con la aplicación de las contrapartidas de la ayuda americana al INC.

\section{TABLA 4}

Proyectos gestionados por el INC procedentes de las contrapartidas de la ayuda

\begin{tabular}{|c|c|c|c|c|c|c|c|}
\hline Proyecto & $\begin{array}{l}\text { 52-12-053 } \\
\text { Acuerdo } 9\end{array}$ & $\begin{array}{l}\text { 52-12-121 } \\
\text { Acuerdo } 29\end{array}$ & $52-12-122$ & $\begin{array}{c}52-12-228 \\
\text { Acuerdo } 112 \\
\end{array}$ & $\begin{array}{c}\text { 52-12-228 } \\
\text { Acuerdo } 145\end{array}$ & $\begin{array}{c}\text { 52-12-228 } \\
\text { Acuerdo } 178\end{array}$ & $\begin{array}{c}52-12-228 \\
\text { Acuerdo } 207\end{array}$ \\
\hline Denominación & $\begin{array}{c}\text { Regadíos } \\
\text { y colonización }\end{array}$ & $\begin{array}{c}\text { Pequeños proyectos } \\
\text { de riego }\end{array}$ & $\begin{array}{l}\text { S Regadíos y } \\
\text { colonización }\end{array}$ & $\begin{array}{l}\text { Regadíos y } \\
\text { colonización }\end{array}$ & $\begin{array}{l}\text { Regadíos y } \\
\text { colonización }\end{array}$ & $\begin{array}{l}\text { Regadíos y } \\
\text { colonización }\end{array}$ & $\begin{array}{l}\text { Regadíos y } \\
\text { colonización }\end{array}$ \\
\hline Ley pública & $\begin{array}{c}\text { PL778 - } \\
\text { Enm. McCarran }\end{array}$ & PL480 & PL480 & PL480 & PL480 & PL480 & PL480 \\
\hline \multirow{2}{*}{ Firma acuerdo } & 4 abril & 25 junio & 28 junio & 30 julio & 15 julio & 24 octubre & 28 diciembre \\
\hline & 1956 & 1956 & 1956 & 1959 & 1960 & 1961 & 1962 \\
\hline $\begin{array}{l}\text { Inversiones } \\
\text { ayuda americana }\end{array}$ & 599,8 Mptas & 100 Mptas & 375 Mptas & 1.000 Mptas & 632,6 Mptas & 700 Mptas & 725 Mptas \\
\hline $\begin{array}{l}\text { Inversiones } \\
\text { Gobierno español }\end{array}$ & 2.703,4 Mptas & 150 Mptas & 562,1 Mptas & 1.011,8 Mptas & 706,7 Mptas & 400 Mptas & 1.174 Mptas \\
\hline Inicio programa & Julio 1955 & Julio 1956 & Julio 1956 & Junio 1959 & Mayo 1960 & Junio 1961 & Octubre 1962 \\
\hline $\begin{array}{l}\text { Final programa } \\
\text { previsto }\end{array}$ & Junio 1958 & Diciembre $1958 \mathrm{Di}$ & Jiciembre 1958 & Marzo 1960 & Abril 1961 & Junio 1962 & Julio 1963 \\
\hline Final programa & Junio & Septiembre & Septiembre & Septiembre & Julio & Octubre & Agosto \\
\hline real & 1958 & 1958 & 1959 & 1960 & 1961 & 1962 & 1963 \\
\hline $\begin{array}{l}\text { Nuevos regadíos } \\
\text { previstos }\end{array}$ & 37.442 ha & 11.000 ha & 52.575 ha & 38.722 ha & 10.222 ha & 13.672 ha & 22.359 ha \\
\hline $\begin{array}{l}\text { Viviendas colonos } \\
\text { previstas }\end{array}$ & 516 & - & - & 2.231 & 902 & 1.779 & 1.513 \\
\hline
\end{tabular}

Fuente: elaboración propia a partir de ACAAA, Ayuda americana, Enmienda McCarran, Convenios y pagos, L480.

54. Dentro de obras de colonización se incluían: la captación de aguas superficiales y subterráneas; pequeñas presas y balsas; redes de riego y desagüe; obras de saneamiento y defensa; caminos; sistematización de tierras, viviendas y núcleos de población.

55. A partir de Ministerio de Agricultura (1966: 355). 
El objetivo perseguido por los siete proyectos firmados y ejecutados entre 1955-1963 era poner en regadío 263.685 hectáreas de tierras de labor y la construcción de 16.695 viviendas para albergar familias de colonos. A 30 de septiembre de 1962 se daban por transformadas en regadío 162.964 hectáreas y por construidas 11.076 viviendas con cargo a la ayuda americana, que se verían aumentadas con la implementación en el territorio de las inversiones del proyecto 52-12-228 ${ }^{56}$. Podría considerarse que en agosto de 1963 la transformación en regadío rondaría las 185.000 hectáreas y las viviendas construidas las 12.500 unidades. Es necesario destacar que el balance de la ayuda no puede circunscribirse únicamente a estos dos indicadores relacionados con las obras de colonización, pues con esta ayuda también se acometieron una gran campaña de exploración y alumbramiento de aguas subterráneas, inédita en la historia de España hasta ese momento y que tanta transcendencia tendría posteriormente en el desarrollo de amplias zonas de la España seca; obras de saneamiento y defensa; carreteras y caminos agrícolas; trabajos de urbanización de los núcleos de población; etc. Como se mencionó antes, si se considera un hipotético funcionamiento en continuo de los pozos y sondeos ejecutados hasta finales de 1959 por el INC, los volúmenes anuales de aguas subterráneas podrían haber alcanzado los $618 \mathrm{hm}^{3}$, muy por encima de los $350 \mathrm{hm}^{3}$ de volumen medio anual trasvasado en sus treinta años de explotación del trasvase Tajo-Segura y próximos a los $619 \mathrm{hm}$ /año de volumen medio anual previstos en el frustrado trasvase del Ebro incluido en el Plan Hidrológico Nacional de 2001. Estos volúmenes alumbrados acumulados alcanzaron a finales de 1965 los $1.331 \mathrm{hm}^{3} /$ año.

Fruto del análisis detallado de los informes trimestrales de seguimiento de cada uno de los proyectos que el INC remitía a la ICA en cumplimiento de los acuerdos, ha podido establecerse el importe de las obras ejecutadas cada año con cargo a la ayuda americana (presentadas en el Gráfico 3 en comparación con el total de las inversiones del INC y las inversiones de dicho organismo solo en obras de colonización). En los años 1960 y 1961 se produjo un descenso de la inversión total de INC, a consecuencia de las medidas de limitación del gasto público y de las emisiones de deuda que introdujo el Plan de Estabilización de 1959 (Serrano \& Pardos, 2002: 370). Ya en 1959 se observa que el crecimiento interanual de la inversión había comenzado a reducirse, tras haberse mantenido casi constante desde 1953. Del mismo modo, respecto de los años anteriores, se produjo un cambio en la tendencia en las inversiones en obras de colonización, que se vieron reducidas en el periodo 1959-1961 a niveles inferiores a los de 1958. La situación de práctica bancarrota (Barciela, 2002: 366) en la que se encontraba el Estado español en 1959, que desencadenó la aprobación del Plan de Estabilización, sumada a los problemas pre-

56. ACAAA, Ayuda americana, Convenios y pagos, Plan de inversiones a cargo de LP480, Proyecto 52-12-228/207, Proyecto 725 Mptas, Acuerdo 112, 28/12/1962, p. 4. 
supuestarios con los que se encontraba el INC a finales de 1958 y el informe crítico con el programa colonizador de la Oficina de Programación y Coordinación Económica (OCYPE) de mayo de $1958^{57}$ pueden permitir entender las causas que motivaron los retrocesos en los niveles de inversión del INC entre 1959 y 1961. Fue precisamente en estos años cuando la ayuda americana alcanzó una mayor transcendencia dentro de las inversiones en obras de colonización, al llegar a suponer un 48\% en 1959, un 67\% en 1960 y un $65 \%$ en 1961 .

\section{GRÁFICO 3}

Evolución de las inversiones totales del INC, del total de las destinadas a obras de colonización y de las obras de colonización financiadas con las contrapartidas de la ayuda americana, 1951-1965

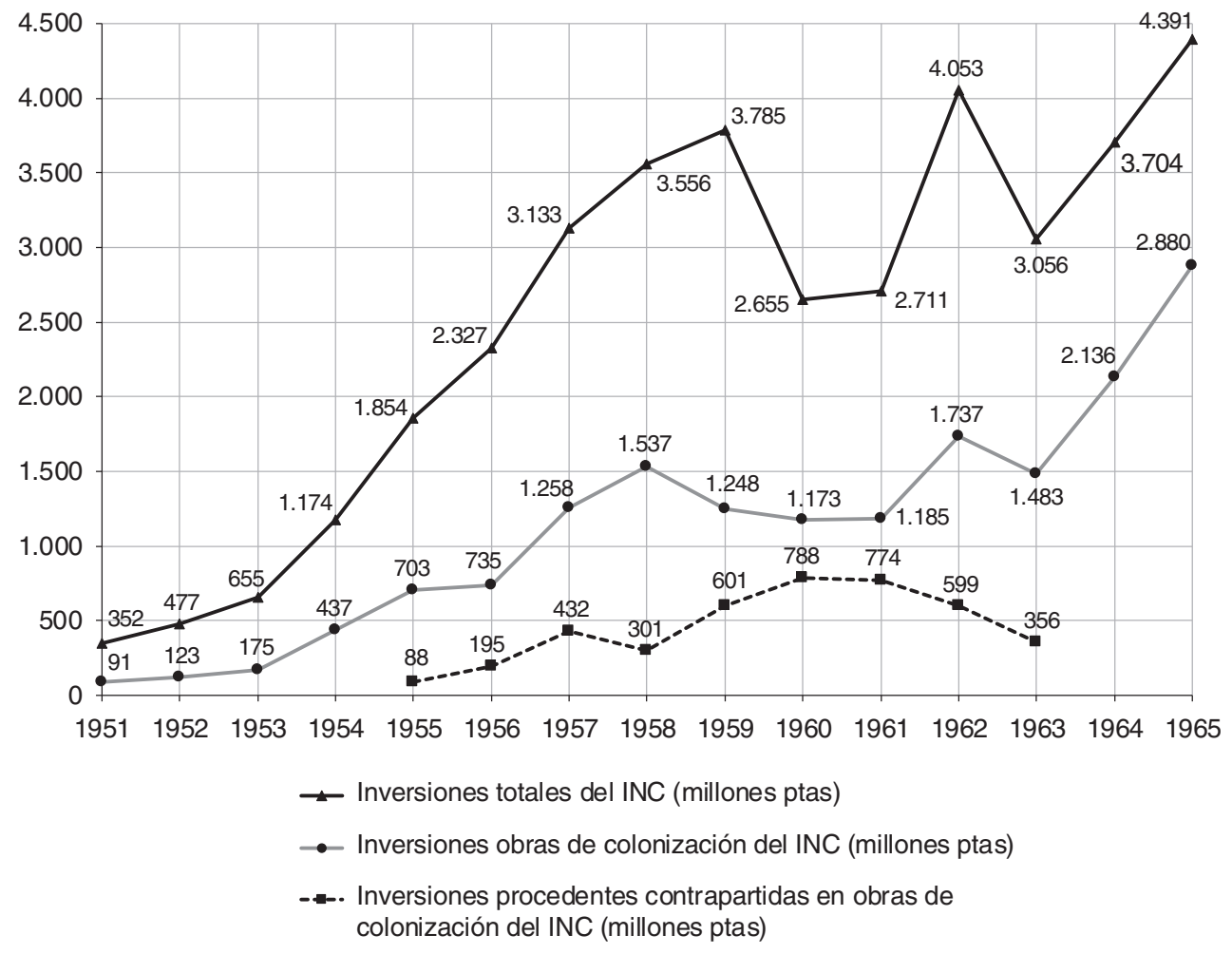

Fuente: elaboración propia a partir de Ministerio de Agricultura (1966), y ACAAA, Ayuda americana, Enmienda McCarran, Convenios y pagos, L480.

57. Véase BARCIELA (1990: 344-349). 
Con el análisis individual de distintos indicadores relacionados con la transformación de tierras llevada a cabo por el INC en el periodo 1939-1965 es fácil comprobar cómo la labor colonizadora vivió una clara inflexión en el año 1954, cuando ya comenzaron a estar disponibles los equipos de movimiento de tierras adquiridos con los programas de importación de la ayuda americana, labor que el INC reforzaría a partir de 1955 con el empleo de las contrapartidas de dicha ayuda. También en estos indicadores puede observarse de una forma clara la ralentización que sufrió la labor del INC entre 1959 y 1961 a causa del Plan de Estabilización (Ministerio de Agricultura, 1966: 80, 162, 170, 172).

\section{CONCLUSIONES}

Sin pasar por alto la transcendencia del conjunto de cambios estructurales a los que se vio sometida la política agraria española durante la década de los cincuenta del pasado siglo, es manifiesta la importancia que tuvo la influencia de los Estados Unidos en su viraje modernizador. El «maná americano» coadyuvó de manera determinante a la reorientación de la política colonizadora. Desde el modelo italiano se pasaría a otro nuevo de inspiración americana que hacía de la obra hidráulica y del aprovechamiento de las plusvalías generadas por las transformaciones el elemento fundamental en la redistribución de la propiedad rústica. Maluquer de Motes (2014: 286-287) ha calificado como poco consistente la repetida afirmación de la baja magnitud de la ayuda americana a España, aparte de valorar, junto con Puig (2005), sus efectos dinámicos en cuanto a las transferencias tecnológicas a la economía y las empresas españolas.

Pero aparte de la importancia cuantitativa de la ayuda, hay que insistir en su relevancia cualitativa, dado su carácter y los efectos inducidos que produciría. La importante transferencia de tecnología que supusieron los programas de importación de maquinaria procedente de los Estados Unidos financiados con la ayuda americana ayudó a superar decisivamente algunos de los cuellos de botella que ralentizaban la modernización del agro hispano y el crecimiento de su productividad. Así ocurrió con la escasez de maquinaria y equipos para el movimiento de tierras, que en la década anterior de los cuarenta se había padecido con particular gravedad. Para explicar tal situación habría que aludir al aislamiento del país y a la incapacidad de la industria de maquinaria nacional para el abastecimiento de las series cortas de maquinaria pesada. Los equipos de procedencia norteamericana, que se adquirieron dentro de estos programas desde 1953, proporcionarían una maquinaria moderna de elevada productividad para ser empleada en las grandes transformaciones agrícolas que el INC efectuaba a través de la sistematización de tierras y las numerosas obras civiles complementarias para el desarrollo de las nuevas zonas regables. Como ha quedado demostrado, esta transferencia tecnológica resultó es- 
pecialmente determinante en el ámbito del aprovechamiento de las aguas subterráneas. La tecnología de explotación de los acuíferos, desarrollada principalmente en California y otros estados norteamericanos en los años treinta y cuarenta del siglo pasado, se expandió por las obras de colonización del INC en el contexto de estos programas de ayudas a la importación. La combinación de mejoras en la perforación de sondeos y en los sistemas de bombeo permitió el acceso a niveles acuíferos mucho más profundos, el aumento de los caudales disponibles y una mayor seguridad y garantía en el suministro. Además, esta transferencia vino acompañada de un programa de asistencia técnica que supuso, mediante la estancia de técnicos estadounidenses en España y de técnicos españoles en Norteamérica, una difusión de los conocimientos y capacidades que están detrás de la organización del Servicio de Aguas Subterráneas del INC.

La aplicación de los fondos de la contrapartida de la ayuda americana a la labor del INC a través de los distintos acuerdos firmados entre ambos países desde la mitad de la década de los cincuenta fue fundamental en la inflexión del programa colonizador. Las inversiones totales en obras de colonización que el INC financió con cargo a las contrapartidas de la PL779 o enmienda McCarran y la PL480 entre 1955 y 1963 alcanzaron los 4.131,6 Mptas, lo que vendría a suponer un $37 \%$ del total de lo gastado por el organismo dependiente del Ministerio de Agricultura en obras de colonización para ese periodo. Esta dependencia de la ayuda americana llegó a ser mucho mayor en los duros años que siguieron al Plan de Estabilización de 1959, alcanzando entre 1960 y 1961 valores próximos al $65 \%$, lo que permitió atenuar los efectos ralentizadores de las restricciones del plan. Puede decirse que como resultado de los siete acuerdos de proyectos gestionados por el INC con cargo a las contrapartidas de la ayuda americana entre 1955 y 1963 la transformación en regadío rondaría las 185.000 hectáreas y las viviendas construidas las 12.500 unidades.

Además, también deben ser señalados los importantes y novedosos trabajos de exploración y alumbramiento de aguas subterráneas que con cargo a esta ayuda se desarrollaron desde 1955 en todo el territorio nacional, pues por primera vez en España se acometió por parte del Estado una campaña intensiva de ejecución de perforaciones profundas (sondeos) para la explotación de aguas subterráneas con destino a la puesta en regadío de grandes zonas, que tan trascendental se ha manifestado en el desarrollo agrícola de las zonas productoras del sureste de la península Ibérica de alta productividad y gran capacidad exportadora (Almería, Murcia, Alicante, etc.). Se podría decir que el fomento desde el Estado de la puesta en regadío de amplias zonas agrícolas con recursos subterráneos fue una novedosa aportación, por su concepción y por su materialización, del Gobierno de la dictadura franquista. Indudablemente la disponibilidad por primera vez en la historia de un paquete tecnológico adecuado condicionaría sobremanera la apuesta del Estado por las aguas subterráneas. 
La ayuda americana en forma de contrapartidas analizadas (PL779 y PL480) funcionó como un mecanismo de coinversión y tuvo un efecto de apalancamiento financiero, puesto que el montante de la compra de excedentes americanos se depositaba en el Banco de España y se destinaba a inversiones finalistas en la agricultura española a través del INC, pero a su vez comprometía al Gobierno español a coinvertir en el sector agrario nacional.

Además, la labor supervisora de la Administración norteamericana en el empleo de estos fondos supone una nueva perspectiva en el análisis de la configuración de la acción pública en el sector agrario en los años cincuenta. El carácter finalista del empleo de las contrapartidas por el INC, orientadas hacia obras de transformación agrícola, estuvo también acompañado por un férreo control por parte de la Administración americana que, de algún modo, se preocupaba así de validar el programa colonizador español. La ayuda americana respondió, sin duda, a un plan organizado que no solo tuvo como destino las grandes zonas regables, sino también el pequeño regadío diseminado, que sería precisamente el área más exitosa en la labor del INC.

\section{AGRADECIMIENTOS}

Este trabajo ha sido financiado parcialmente por el proyecto HAR2014-56428-C3-2-P del Ministerio de Economía y Competitividad. Los autores agradecen los comentarios recibidos en el IV Workshop "Cooperación y conflicto en el mundo rural: Estado y agricultura en España (1920-1960): continuidad y cambios», organizado por el Instituto Figuerola de Historia y Ciencias Sociales de la Universidad Carlos III de Madrid en noviembre de 2014, así como la ayuda de Bienvenido Marzo López, de Cajamar Caja Rural, y de Pilar Bravo Lledó, Juan Manuel García Bartolomé y Diego Medina Vela, del Ministerio de Agricultura, Pesca y Alimentación, por facilitar nuestro trabajo en Madrid y San Fernando de Henares. Asímismo, la redacción final se ha beneficiado de los comentarios de los revisores y editores de Historia Agraria, a los que queremos agradecer su colaboración.

\section{REFERENCIAS}

AguiRre, J. (1956). Subsoladores para labores profundas sin volteo de tierras. Madrid: Instituto Nacional de Colonización, Ministerio de Agricultura.

ÁlvARO, A. (2011). Inversión directa extranjera y formación de capacidades organizativas locales: Un análisis del impacto de Estados Unidos en la empresa española (1918-1975). 
Tesis doctoral. Madrid: Universidad Complutense de Madrid.

Álvaro, A. (2012). La inversión directa estadounidense en España: Un estudio desde la perspectiva empresarial (c. 1900-1975). Estudios de Historia Económica, (60), 1-147. AsociaCión NACIONAL DE INGENIEROS AgRóNOMOS (1950). Energía y maquinaria agrícolas. En I Congreso Nacional de Ingeniería Agronómica. Madrid: Asociación Nacional de Ingenieros Agrónomos.

BALDRICH, A. (1957). Balance y efectos económicos de la ayuda norteamericana. Moneda y Crédito, (61), 27-46.

Barciela, C. (1986). Introducción. En R. Garrabou, C. BARCiela \& J.I. JimÉnez Blanco (Eds.), Historia agraria de la España contemporánea. 3. El fin de la agricultura tradicional (1900-1960) (pp. 383-454). Barcelona: Crítica.

BARCIELA, C. (1990). Parte II: Aproximación a los elementos básicos para una historia financiera del Instituto Nacional de Colonización. En Historia y evolución de la colonización agraria en España. II: Políticas administrativa y económica de la colonización agraria: Análisis institucional y financiero (1936-1977) (pp. 226-349). Madrid: Ministerio para las Administraciones Públicas/Ministerio de Agricultura, Pesca y Alimentación/Ministerio de Obras Públicas y Urbanismo.

BARCIELA, C. (2002). Guerra Civil y primer franquismo (1936-1959). En F. Comín, M. HERNÁNDEZ \& E. Llopis (Eds.), Historia Económica de España: Siglos X-XX (pp. 331367). Barcelona: Crítica.

Barciela, C. (2012). Los años del hambre. El País, 5 de febrero.

BARCiela, C. \& López OrTiz, M. I. (2000). La política de colonización del franquismo: Un complemento de la política de riegos. En C. Barciela \& J. Melgarejo (Eds.), El agua en la historia de España (pp. 323-363). Alicante: Universidad de Alicante.

BARCiEla, C. \& López OrTiz, M. I. (2003). El fracaso de la política agraria del primer franquismo, 1939-1959:Veinte años perdidos para la agricultura española. En C. BARCIELA (Coord.), Autarquía y mercado negro: El fracaso económico del primer franquismo, 1939-1959 (pp. 55-94). Barcelona: Crítica.

Calvo, O. (2001). ¡Bienvenido, Míster Marshall! La ayuda económica americana y la economía española en la década de 1950. Revista de Historia Económica-fournal of Iberian and Latin American Economic History, 19 (1 núm. extraordinario), 253-275.

Clavera, J., Esteban J. M., Monés, M. A., Montserrat, A. \& Ros, J. (1976). Capitalismo español: De la autarquía a la estabilización (1939-1959). Madrid: Edicusa.

DeBlois, E. N. (1967). 12 Years of Achievement under Public Law 480. Washington, DC: US Department of Agriculture.

Delgado, L. (2003). ¿El «amigo americano»? España y Estados Unidos durante el franquismo. Studia Histórica-Historia Contemporánea, (21), 231-276.

DíAz BERENGUeR, E. A. (1982). La ayuda americana a España durante los años cincuenta y sesenta, con especial referencia a la P. L. 480: Efectos sobre la economía española en 
general y sobre el sector agrario en particular. Tesis doctoral. Madrid: Universidad Politécnica de Madrid.

Díaz Pines, O. (1963). Instituto Nacional de Colonización. Revista Temas Españoles, (320).

GARRABOU, R. (1990). Sobre el atraso de la mecanización agraria en España (1850-1933). Agricultura y Sociedad, (57), 41-77.

Gómez BENITO, C. (2007). Modernización agraria, modernización administrativa y franquismo: El modelo educativo y administrativo del Servicio de Extensión Agraria (1955-1986). Áreas: Revista Internacional de Ciencias Sociales, (26), 131-149.

González Asensio, A. (2013). Aurelio Domínguez Martín. En J. A. LóPez-Geta \& J. M. ForNÉs (Eds.), 100 Años de Hidrogeología en España: 1900-2000 (p. 531). Madrid: Instituto Geológico y Minero de España.

LARRÚ, J. M. (2009). El «Caso España»: Un repaso a la ayuda norteamericana recibida por España en perspectiva actual y comparada. Estudios Económicos de Desarrollo Internacional, 9 (1), 91-126.

MALUQUeR DE MOTES, J. (2014). La economía española en perspectiva histórica: Siglos XVII-XXI. Barcelona: Pasado y Presente.

Mangas, J. M. (1990). Parte I: La política de colonización agrícola del franquismo (1936-1977): Introducción. En Historia y evolución de la colonización agraria en España. II: Políticas administrativa y económica de la colonización agraria: Análisis institucional y financiero (1936-1977) (pp. XXVI-XL). Madrid: Ministerio para las Administraciones Públicas/Ministerio de Agricultura, Pesca y Alimentación/Ministerio de Obras Públicas y Urbanismo.

MARTínez Borque, A. (1948). La colonización de los regadios del oeste de los Estados Unidos de América: Informe e impresiones de un viaje. Madrid: Instituto Nacional de Colonización, Ministerio de Agricultura.

Martínez Rodríguez, F. J. (2014). Cambio tecnológico en el aprovechamiento de las aguas subterráneas en la España de la segunda mitad del siglo Xx: Madurez e iniciativa estatal. TST: Transportes, Servicios y Telecomunicaciones, (27), 262-298.

Martínez Rodríguez, F. J. \& SÁnchez Picón, A. (2016). La hora de las aguas subterráneas en la España del siglo xx: Transferencia tecnológica e iniciativa estatal. Trabajo presentado en el Congreso Internacional «Old and New Worlds: The Global Challenges of Rural History». Lisboa, 27-30 de enero. https://lisbon2016rh.files.wordpress .com/2015/12/onw-02491.pdf

MARTíNeZ Ruiz, J. I. (2000). Trilladoras y tractores: Energía, tecnología e industria en la mecanización de la agricultura española (1962-1967). Sevilla: Universidad de Sevilla/Universitat de Barcelona.

Ministerio de Agricultura (1966). Instituto Nacional de Colonización: Memoria: Octubre 1939-diciembre 1965. Madrid: Ministerio de Agricultura. 
Ministerio de Medio Ambiente y Medio RuRAly Marino (2008). España se prepara. En Centro de Publicaciones, Secretaria General Técnica (Ed.), Fondo documental histórico cinematográfico, (2).

Prados de la Escosura, L. (2003). El progreso económico de España (1850-2000). Bilbao: Fundación BBVA.

Puig, N. (2003). La ayuda económica norteamericana y los empresarios españoles. Cuadernos de Historia Contemporánea, (25), 109-129.

Puig, N. (2005). La ayuda económica de Estados Unidos y la americanización de los empresarios españoles. En L. Delgado \& M. D. Elizalde (Eds.), España y Estados Unidos en el siglo XX (pp. 181-205). Madrid: Consejo Superior de Investigaciones Científicas.

SERrano, J. M. \& PARdos, E. (2002). Los años del crecimiento del franquismo (19591975). En F. Comín, M. HernáNDEZ \& E. Llopis (Eds.), Historia económica de España: Siglos $X-X X$ (pp. 369-395). Barcelona: Crítica.

SHEARER, E. B. (1959). Significado para España de la ayuda económica norteamericana. Revista de Economía Política, 10 (3), 989-1006.

VIÑas, A. (2003). En las garras del águila: Los pactos con Estados Unidos, de Francisco Franco a Felipe González (1945-1995). Barcelona: Crítica.

YbarRa, M. J. (2004). Washington Gone Crazy: Senator Pat McCarran and the Great American Communist Hunt. Hanover: Steerforth Press.

ZAmagni, V. (2011). Historia económica de la Europa contemporánea: De la Revolución Industrial a la integración europea. Barcelona: Crítica. 